cm. high and $180 \mathrm{~cm}$. broad. The space between
the wooden jacket and the iron still is filled with ashes the atmosphere within the bath by means of
the tubes; and experiments are quoted to show that to the exclusion of the air. A temperature of $48^{\circ} \mathrm{C}$. is
thet only is evaporation rapid, but the temperature at
not

required for the distillation, and is produced by the
introduction of steam between a double base or bottom.

The vapor of the carbon bisulphide passes off
through a tube and is condensed in a row of four cool bon bisulphide is collected beneath water. The filling and clearing of the vessel may be accomplished by means of a small aperture at the top of the vessel. charging, 40 to 50 hectoliters of raw carbon bisulphide to 0.5 atmospheric tension. Ahout two hours after the distillation commences, which is very strongly evidenced by the heat of the exit tube, while a hissing is heard in the condenser, sulphureted hydrogen be ing also liberated at the earliest stage of the operation dual sulphur in the vessel must be cleared out with wooden scoop. It is in this operation that the workman is exposed to the escaping vapors of carbon bisul-
phide, and is thereby very seriously affected. The tructive reaction of carbon bisulphide upon the organism is indeed so considerable that, as Clocz states, as small a volume as 5 per cent. of the vapor in the air is
sufficient to kill the smaller mammalia, as well as birds and reptiles. The workman suffers from headache vomiting, and has irresistible fits of weeping, soon feelfinally all his bodily and mental powers are paralyzed or much impaired, and loss of memory is noticed to ensue. It has happened even that the workman lapse into idiocy.

lt has been tried to expel the $\mathrm{CS}_{2}$ and other substances present out of the residual sulphur by raising
its temperature considerably. But as the vessel can only stand a pressure of half an atmosphere, the diffilled three parts with water and steam letdirectly in to the liquid. The water is brought up to boiling, and
the carbon bisulphide is thus distilled over. The heat ing occupies about 20 hoúrs, whereupon the water can be drawn off and the sulphur removed without any
ranger. This residual sulphur is used up again in the

The refined carbon bisulphide is removed $15 \mathrm{hk}$, at time and stored up under water in sheet-iron cylinder holding about 30 to $80 \mathrm{hk}$. The supply is executed in 500 or 100 kilogramme lots, in wrought iron and air tight . cylinders. For the first quantities a space of
about 12 liters, for the latter 25 liters, to allow for the
expansion of the carbon bisulphide.

The total production of the refined carbon bisulphide is taken over by the Hungarian Agricultura Secretary of State for 18 florins per hectoliter and distributed among the schools for vine culture and other phylloxera.

The cost of production is from two to three florins (four to six shillings) per hectoliter. Up to 1889 onl since the enlargement of the works the process is generally carried on in three retorts out of four simul-

The annual production of raw $\mathrm{CS}_{2}$, with one oven, is
taneous y. 1,102 hectoliters. The total production per annum taking the pure at 80 per cent - at 3,500 hectoliters which corresponds approximately to the present consumption in Hungary. $\mathrm{CS}_{2}$ is a very complicate The production of the raw $\mathrm{CS}_{2}$ is a very complicated
and dangerous process, so much so that at first the and dangerous process, so much so that at first the
utmost difficulty was experienced to obtain any workutmost difficulty was experienced to obtain any work-
men to perform the operation. Besides the use exmen to perform the operation. Besides the use ex-
plained in this article, it is also used for the extraction of oils from seeds, etc., solution of resinous substances,
alkaloids, phosphorus, and sulphur.-Zeit. f. angw. Chem.

A NEW FORM OF AIR BATH.

By E. Sauer. J. Amer. Chem. Soc.

Is order to insure a constant temperature, which
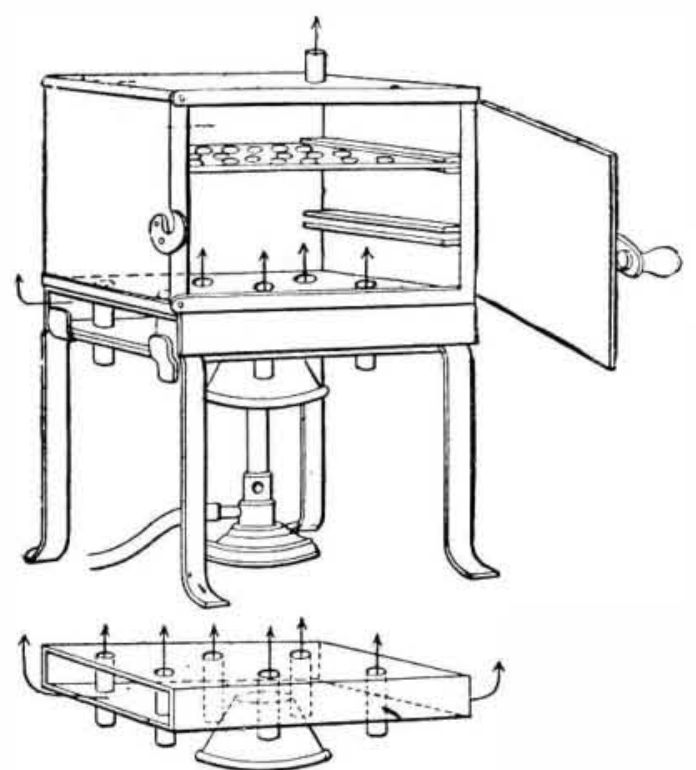

\section{DROPPING FLASK FOR STANDARD} SOLUTIONS.

By F. Vanderpoed. J. Amer. Chem. Soc.

ThE use of burettes for standard solutions involve serious errors (e. g., such as arise from alterations of
tenperature), which can be avoided by substituting

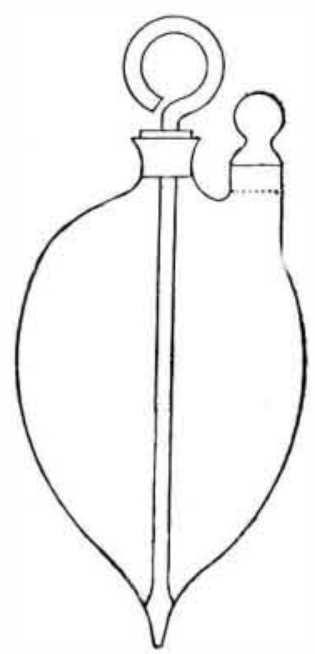

weighing for measuring. The figure shows a simple orm of dropping flask for standard solutions, which
has been found convenient. The figure is almost self. is of glass, and passes through a cork in the upper tube, thus serving to regulate the ourflow. The side tubulus is used for filling the flask. The whole apparatus can be slung to a hook on the balance, or sup bottle.

MPROVEMENTS IN THE PRODUCTION OF CHLORINE AND REFINED LEAD AND RECOVERY OF SILVER.

By F. M. Lyte, London.

LEAD chloride is formed from yellow lead oxide

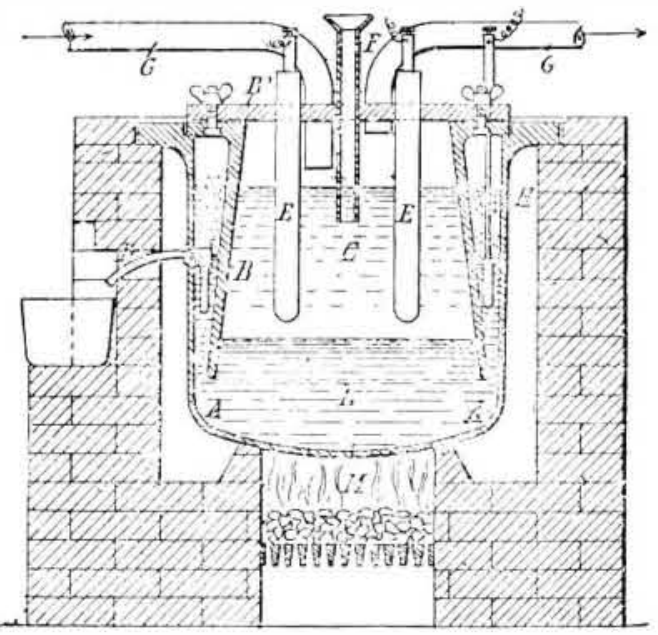

with an excess of aqueous hydrochloric acid, in a pan having a granite bottom and stoneware sides; or which is shown, in which stone mullers are carried
round by cross arms and stay rods of a frame revolvround by cross arms and stay rods of a frame revolv-
ing on a center. and resting at their outer ends on rollers on a circular rail supported by adjusting serew to regulate the grinding action. Silver chlorie may acid or solution of a suitable alkaline-earthy chloride and on filtering the warmed solution through spongy lead, silver is deposited. Or the argentiferous lead chloride may be fused over lead, the chlorides being
used in successive charges until the lead is sufficiently enriched for recovery of the silver by cupelation. Crude lead may be oxidized in a basic-lined Bessemer converter, in which a high temperature is atsmall proportion of lead that escapes oxidation. The litharge and fume in the manner first described.

litharge and fume in the manner first described.
Lead chloride may be purified by solution in hot water and crystallization, the same water or mother washed dried, repeatedly used. The washed, dried, fused and electrolytically decomposed appe iron pan, A, set over the furnace, M, contains ead, $L$, into which the earthenware or $\mathrm{B}$. dips, the lead being melted to receive it, and the chloride by removing the cover, $B^{1}$ and afterward are carbon anodes, each hollowed to receive a fusible metal core, preferably of lead. connected to the con-
ducting wires. $\mathrm{H}$ is the cathode terminal dipping ducting wires. $\mathrm{H}$ is the cathode terminal dipping composition of the chloride, it runs off by the pipe, $D$ series, the chlorine entering from another cell by the feature of the invention that the air in the ceil should be displaced by a non-oxidizing gas, as chlorine or nitrogen, in ord
in the process.
FLAMES IN FOUL AIR

AT the last meeting of the Federated Institution of Mining Engineers, Dr. Frank Clowes read a paper on Air which is Extinctive to Flame." It contained a suggestion of a method for ascertaining the limit of afety of mixtures of carbon dioxide and air. It appears from Dr. Clowes' own experiments. in which of carbon dioxide was determined from a variety of aked flames, that candles and ordinary lamp flames, nclusive of colza and petroleum and ordinary lam paraffin, cannot live in an atmosphere containing frou
14 to 16 per cent. of added carbon dioxide. On the other hand, the flame of burning hydrogen is not extinguished until 58 per cent. of carbon dioxide has been cent. of added carbonic acid. Methane will only stand 10 per cent., while carbonic oxide will endure 24 per lamp in which a flame of hydrogen was burning at the side of an oil flame, and he showed the superior thdurance of the former when exposed to vitiated air. He concluded by remarking that the wisdom of at tem pting to pass through foul air in mines, wells, etc. has been questioned, because it has been assumed that to extinguish the oil flame of a safety lamp would necessarily be irrespirable, or at least dangerous to life Experiments recently conducted by Mr. T. $\mathrm{H}$. Wilson, however, have gone to prove that rabbits can breathe
with impunity for an hour at least air containing 25 per
cent of carbon dioxide cent. of carbon dioxide. The presence of 16 per cent. of
this impurity extinguishes the ordinary safety lamp this impurity extinguishes the ordinary safety lamp
flame. Hence it appears that respiration can be mainflame. Hence it appears that respiration can be main-
tained unimpaired in air containing at least 10 per cent. more choke damp than is sufficient to extinguish the oil or alcohol flame of a safety lamp. If Mr.Wilson's experiments are accepted, it would evidently be well to have
ome test less sensitive than the ordinary safety lamp lane to indicate whether an atmosphere contain sufficient carbondioxide to be dangerous to life. Since
the flame of ethylene is only extinguished with 26 per
cent. of added carbon dioxide, such a flane might serve the purpose. It is worthy of notice, in this concontinue to burn in air that has long passed the limits of added carbon dioxide compatible with the preservation of human life.

THE ALKALOIDS OF COD LIVER OIL AMONG the exhibits in the museum at the recent particularly interesting specimen was a subs hibited by Messrs. F. Stearns \& Co of Detroit, under the name of "Panjecorine." As the name signifies this was a specimen of the total alkaloids contained in
a sample of cod liver oil. This subject was first taken a sample of cod liver oil. This subject was first taken
up by MM. Gautier and Mourgues, who published in 1890 (Journ. de Pharm., March, 1890) a detailed account of their experiments and the substances extracted by
then front the oil. These were butyl, anuyl, and hexyl amines, dihydrotoluidine, aselline, morrhine and morrhuic acid (the gaduine of De Jongh); the latter cho being the most important bodies. In reply to products, an article appeared in the Comptes Rendus (November, 1892), from the pen of M. Bouillot, show ing that by the aid of gaseous hydrochloric acid and platinum perchloride the alkaloidal bodies could be
crystallized in situ in the fresh liver, and their form identified with that of the bodies extracted from th bodies are shown below. The subject is being followed up by Professor Schlotterbeck, of the University of Michigan, who has confirmed the results of MM. Gautier and Mourgues, and who prepared the specimen exhibited at Bristol. Up to the present a ready method of separating the various constituents fron pear-at all events as far as the medical activity of the
bodies is concerned-to be any necessity for separating

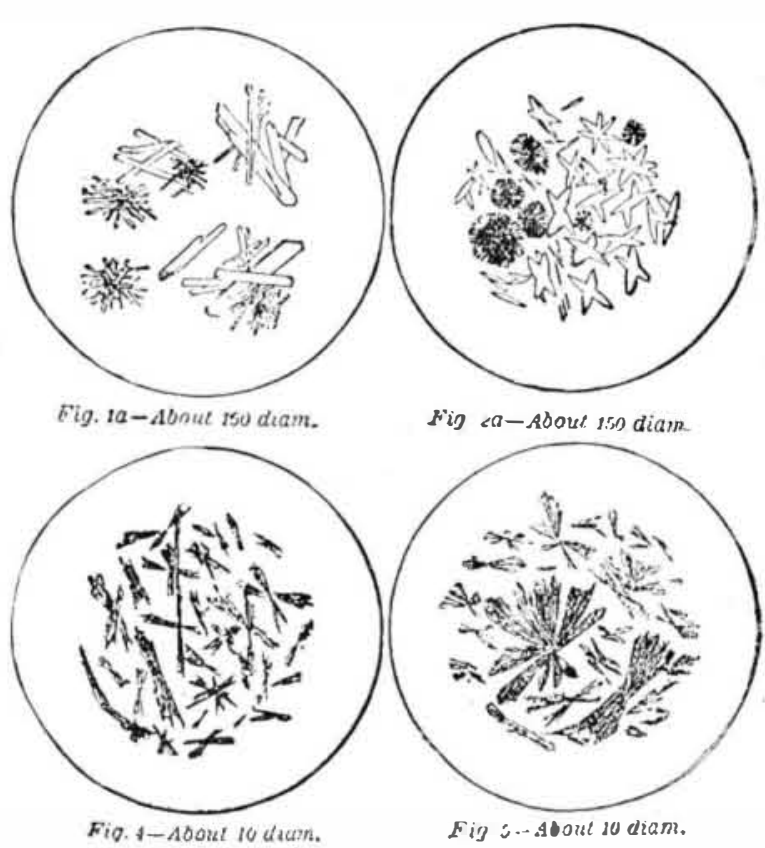

the mixed bases further. The total combined alkaoids or "Panjecorine" have so far proved to be quite poved whether or not the residual oil has any medicinal value. Professor Schlotterbeck is preparing a (her for theoming meeting of the Aun can Pharmaceutical Association. The combined alkaStearns are utilizing this property in preparing a wine of cod liver oil, which clinical reports state to be quite ant taste. 